\title{
Assess the Prevalence and the Risk Factor of Obesity among the School Age Children at Mandrail in Rajasthan
}

\author{
Vivek Kumar Sharma', Mary Minolin² \\ ${ }^{1}$ Bachelor of Science in Nursing, Saveetha University, Chennai 602 105, India \\ ${ }^{2}$ Assistant Professor, Department of Child Health Nursing, Saveetha College of Nursing, Chennai -77, India
}

\begin{abstract}
Introduction: Obesity is a condition in which the natural energy reserve stored in the fatty of human and other mammals is increased to a point where it is associated with certain health condition or increased mortality. Obesity is a state in which there is generalized accumulation of excess fat in the body leading to a body weight of more than $20 \%$ of the required weight. Obesity invites disability, disease and premature death. Objective: Assess the prevalence of obesity among school children aged 15 to 19 year. Find out the risk factor of obesity in school age children. Find out association the demographic variables with obesity in school children. Methodology: Descriptive cross sectional research design was adopted. Non probability convenience sampling technique was used to 30school age children were selected bright star school. The data was collected organized and analyzed in term of descriptive statistics. Result: The study findings showed that a majority of them i.e. 0[0\%] who had adequate knowledge, 9[30\%] who had moderate knowledge, 21[70\%] who had inadequate knowledge. Keys: obesity, obesity school children
\end{abstract}

Keywords: obesity, school age children

\section{Introduction}

Historically, a fat child means a healthy child, one who is likely to survive the rigors of under nourishment and infection. But unlike the past, today obesity or overweight in childhood is considered as a major health risk condition developed mainly due to malnutrition and improper lifestyle and which can lead to a number of health problems both in childhood and later in adulthood. According to Swaminathan (1) a person whose body weight is higher than normal by 15 $20 \%$ is considered as obese. A child is considered as obese when the total body weight is more than $25 \%$ fat in boys and $32 \%$ in girls ${ }^{(2) .}$

Overweight is associated with the onset of major chronic diseases leading to complications and also psychosocial problems in children and adults. The greater concern is that the risks of overweight during childhood will persist into adolescence and adulthood. Tackling the problems of the growing numbers of overweight prevalence in children and adolescents and taking timely preventive measures will be an effective approach in dealing with the problem of obesity.

During the past two decades, the prevalence of obesity in children has risen greatly worldwide and this excessive fatness has arguably become a major health problem of both developed and developing countries. Obesity during childhood is a matter of growing concern in India also. Most individuals develop their eating and activity patterns during childhood. The transition in nutrition and lifestyle by the popularity of fast foods, soft drinks, sedentary life style, and lack of exercise, increased television watching and computer use are the common trends adopted by children today.

Review of the situation in 2001 prior to the formulation of the 10th Five Year Plan (Planning Commission, 2002) showed that although under nutrition and micronutrient deficiencies continue to be major public health problems, over nutrition and obesity are also emerging as a major problem in many states. There is a paradigm shift in the quality of life in urban population. It is observed that $30 \%$ of obesity begins in childhood and out of that $50 \%$ to $80 \%$ become obese adults (3). In the Harvard study, morbidity from cardiovascular disease, diabetes, obesity related cancers and arthritis was $50 \%-100 \%$ higher in obese individuals who were also obese as children (4).

With the increase in obesity prevalence there is a parallel increase in obesity associated chronic diseases and their clinical onset at ever younger ages. The obesity has reached an epidemic proportion in urban Indian population. The obesity has been defined as a condition of abnormal or excessive fat accumulation in adipose tissue, to the extent that health may be impaired (WHO consultation on obesity 2000) (3).

Epidemiological studies have shown a progressive increase in the incidence of hypertension, diabetes mellitus and coronary heart disease, sleep apnea syndrome, and certain cancers in obese persons. Epidemiological and metabolic studies connected over the last 15 years have confirmed the notion that a high proportion of abdominal fat (central obesity) is a major risk factor for coronary heart disease, type2 diabetes mellitus, and related mortality(7).Epidemiological studies have mainly used ratio of waist -to-hip circumference (waist: hip ratio)to estimate the proportion of abdominal adipose tissue. Visceral obesity is associated with insulin resistance and glucose intolerance $(8,9,10)$.Apart from this, these persons are associated with dyslipoprotenemias and other metabolic derangements.

There are several reasons for obesity during childhood like overfeeding, commercial baby foods, junk foods, and 


\section{International Journal of Science and Research (IJSR) \\ ISSN (Online): 2319-7064}

Index Copernicus Value (2015): 78.96 | Impact Factor (2015): 6.391

lifestyle of the family, spending more time with television and computer and inadequate play areas.

\section{Need for the Study}

Childhood obesity is a global health problem recognized by the WHO. Prevalence of obesity in school aged children is estimated to be $30 \%$ worldwide. One out of 5 children in India is overweight or obese - a total of 9 million children (CDC, 2006). The prevalence of overweight and obesity has nearly tripled among adolescents (12 to 19 years old) and quadrupled among younger children (6 to 11 years old). Life-threatening health problems once diagnosed in adulthood-type 2 diabetes, high blood pressure, and high cholesterol-are increasing among children and adolescents. These conditions threaten to decrease the life expectancy of today's children and to bankrupt the nation's healthcare system. It is not just a matter of overeating and underexercising, although that's part of the problem. A convergence of factors such as genetic, behavioral, nutritional, socioeconomic, political and environmental has created a public health catastrophe for adults and children. Over the past 30 years, what, how, when, and where we eat and where and how families live, work, and play have undergone enormous change. Aggressive marketing of cheap high-fat, high-sugar foods, particularly to children; the fast-food invasion of school cafeterias, too much television and video gaming; too little exercise; and manipulation of nutritional messages by the food industry have together widened the waistlines of children and narrowed their chances for a healthy future.

Halting this multifaceted epidemic will not be simple; there is no one quick fix. Solutions must involve changes by individuals, communities, and society. Nurses and other health professionals, parents, teachers, and policy makers all need to be informed and involved in making change. Motivating change begins with understanding the causes and consequences of obesity and implementing programs and policies that will reverse the epidemic.

Being overweight or obese has serious short- and long-term consequences for individuals and for society. In the short term, overweight or obese children are at higher risk for type 2 diabetes, asthma, liver disease, sleep problems, and impaired cognitive function than other children . They may also face teasing, bullying, and discrimination in school and social settings leading to low self-esteem and depression. In the long term, overweight children are more likely to become obese adults with serious, even life-threatening, chronic conditions such as type 2 diabetes, cardiovascular disease, stroke, and increased risk of Alzheimer's disease. Overweight and obesity increase the risk of breast cancer in women and prostate cancer in men. Recent studies also suggest that cancer of the esophagus and upper stomach also may be linked with obesity. The incidence of both of these cancers is increasing in industrialized countries. One study that tracked more than 40,000 people for an average of 11 years found that obese individuals had 4 times the risk of esophageal cancer or upper stomach cancer than individuals of normal weight.
Harvard scientists reported that obesity at age group 6-10 years was associated with a greater than two-fold increased risk of multiple sclerosis. This was a large prospective study using data from the Nurses' Health Study. The researchers wrote, "Although the mechanisms of this association remain uncertain, this result suggests that prevention of adolescent obesity may contribute to reduce multiple sclerosis risk."

Obesity may also increase the risk of serious complications from H1N1 influenza. A study in California showed that about $25 \%$ of the people hospitalized for H1N1 complications were morbidly obese, even though morbidly obese individuals account for less than $5 \%$ of the U.S. population. Of the 156 obese people hospitalized for H1N1, 46 died. Two-thirds of obese patients had underlying health problems, the most common of which were chronic lung disease, heart disease and diabetes.

Overweight and obese people still face tremendous discrimination in education, employment, and other areas of life. Dealing with discrimination can be a major stressor leading to depression and social isolation. The built environment includes our homes, schools, workplaces, parks/recreation areas, business areas, and roads. The built environment-where we live, work, play, and go to school-has a major influence on many aspects of public health, including obesity. Many aspects of today's built environment do not encourage walking, biking, or other physical activities. Low-income urban neighborhoods often lack safe playgrounds, green spaces, and readily available healthy foods. The only open spaces available may be trashstrewn vacant lots or abandoned industrial sites. Schools in low-income neighborhoods are often poorly funded, with limited space for physical activity. Many are surrounded by fast-food outlets and corner stores that sell high-calorie, lownutrient snacks and other foods.

A study in Philadelphia found that the most frequently purchased items by primary school children were lownutrient foods and beverages such as chips, candy, and sweetened beverages, averaging 360 calories per purchase .Studies suggest that residents with limited access to fastfood restaurants tend to have healthier diets and lower levels of obesity compared to residents of low-income neighborhoods. However, many suburban neighborhoods have no sidewalks, bike lanes, or walking trails, so children are driven everywhere. Only $25 \%$ to $50 \%$ of children walk to school. Although some school cafeterias get a failing grade in nutrition, others are working hard to serve healthy meals for breakfast and lunch and to banish junk food from the premises.

According to a new survey, most parents want schools to limit students' access to high-calorie, low-nutrient chips, sodas, and candy and to provide more opportunities for physical activity throughout the day. More than $90 \%$ of parents surveyed agreed that physical activity and healthy eating have a positive effect on learning. New recommendations from the Institute of Medicine (IOM, 2009b) for federal programs that provide breakfast and lunch in primary and secondary schools include calorie limits. Breakfasts should total between 500 and 800 calories depending on the grade; and lunches should not exceed 650 


\section{International Journal of Science and Research (IJSR) \\ ISSN (Online): 2319-7064}

Index Copernicus Value (2015): 78.96 | Impact Factor (2015): 6.391

calories in grades $\mathrm{KG}$ through five, 700 calories in middle school, and 850 for grades 9 through 12.The IOM also recommends that schools increase the amount and variety of fruits and vegetables offered. Juice should account for no more than half of the fruit provided. The IOM also advises schools to provide whole-grain products rather than the refined type and switch from whole or $2 \%$ milk to $1 \%$ or nonfat milk.

A study was designed to test the effectiveness of a school network for childhood obesity prevention (SNOCOP) in private primary schools; a program that aimed to improve student behavior in terms of knowledge, attitude, intention towards obesity prevention, and their food consumption behavior. A quasi-experimental pre/post test time series study was conducted. By 2-stage stratified sampling selection 180 students from 6 schools were assigned to the intervention group and 195 students from 6 schools to the control group at Delhi. In addition, thirty-one participants being school administrators, teachers, parents, and community members from six schools formed the social network initiating the intervention. The school children in the intervention group improved their eating behavior, knowledge, attitude, intention towards obesity preventive behavior. The six schools of the intervention group changed school policies and school activities aiming to reduce the proportion of obesity among their student. No such activities could be observed in the control group. These findings suggest that the School-Social Network of Childhood Obesity Prevention program is an effective means to prevent childhood obesity.

A study was conducted to implement a school based health promotion programme aimed at reducing risk factors for obesity and to evaluate the implementation process and its effect on the school. In this study the data was collected from 10 primary schools participating in a group randomized controlled crossover trial were pooled and analyzed 634 children (350 boys and 284 girls) aged 7-11 years were participated. Response rates to questionnaires were teachers' evaluation of training and input, success of school action plans, content of school meals, and children's knowledge of healthy living and self reported behavior. A high level of support for nutrition education and promotion of physical activity was expressed by both teachers and parents. Nineteen out of 20 teachers attended the training, and all reported satisfaction with the training, resources, and support. Intervention children showed higher score for knowledge, attitudes and self reported behavior for healthy eating and physical activity.

This programme was successfully implemented and produced changes at school level that tackled risk factors for obesity. Childhood obesity is one of the most serious public health challenges of the $21^{\text {st }}$ century. The problem is global and is steadily affecting many low- and middle-income countries, particularly in urban settings. The prevalence has increased at an alarming rate. Overweight and obese children are likely to stay obese into adulthood and more likely to develop non communicable diseases like diabetes and cardiovascular diseases at a younger age. Overweight and obesity, as well as their related diseases, are largely preventable. Prevention of childhood obesity therefore needs high priority.

As the teachers play a primary role in shaping the behavior of the child, the investigator felt that there is a need to assess the knowledge and attitude of the school children regarding childhood obesity. This study will help us to understand their level of knowledge and attitude of children according to which the educational programme can be planned and implemented in order to prevent childhood obesity ${ }^{4}$.

\subsection{Statement of the Problem}

Assess the prevalence and risk factor of obesity among school age children.

\subsection{Objectives}

1) To assess the prevalence of obesity among school children aged 15 to 18 years.

2) To assess the risk factor of obesity in school age children.

3) To assess the demographic variable with obesity in school children.

\subsection{Operational Definitions}

\section{1) Life style associated risk factors :}

Factors which are associated with the life style of a person and increase his/her risk of developing diseases. In this study it refers to factors which are associated with the life style of railway employees and increase their chance of developing obesity such as lack of physical activity, use of high fat diet.

\section{2) Prevention}

In this study it refers to the measures that to be adopted by the railway employees to prevent the occurrence of obesity such as reduction of body weight, regular program of physical activity, dietary modification with high fiber.

\subsection{Assumptions}

1) The level of knowledge and attitude of the children vary from individual to individual.

2) Mass media influences the level of knowledge and attitude of the children regarding childhood obesity.

3) The level of knowledge and attitude influences each other.

\section{Review of Literature}

Obesity has reached epidemic proportions globally. Significantly, obesity is increasing rapidly in developing countries undergoing rapid nutrition and lifestyle transition, and it often coexists with under-nutrition. The rising prevalence of obesity in developing countries is largely due to rapid urbanization and mechanization which has led to reduction in the energy expenditure along with an increase in energy intake due to increased purchasing power and availability of high fat, energy-dense fast foods ${ }^{11}$. Obesity is associated with increased risk of the metabolic syndrome, type 2 diabetes mellitus (T2DM), hypertension, dyslipidemia, polycystic ovarian syndrome (PCOS), and 


\section{International Journal of Science and Research (IJSR) \\ ISSN (Online): 2319-7064}

Index Copernicus Value (2015): 78.96 | Impact Factor (2015): 6.391

coronary heart disease (CHD) and some of these metabolic derangements start in childhood.

The Literature Review will provide information on various topics related to childhood obesity as follows:

1) Studies regarding incidence and prevalence of childhood obesity.

2) Studies related to effects of dietary patterns on obesity.

3) Studies related to prevention of childhood obesity at school levels.

1) Studies regarding incidence and prevalence of childhood obesity

A study was conducted in schools at Delhi on 3800 school children. Study revealed that children over 85 th percentile as per BMI chart were considered overweight. Analysis of the data collected revealed that over $17 \%$ children were found to be overweight .Some even had high blood pressure and a family history of diabetes. At least $11 \%$ children preferred eating lunch from the school canteen, over $81 \%$ children claimed that they went out to a fast food joint at least once a week, $62 \%$ children liked eating junk food like burgers, pizzas, etc; and $47 \%$ children took at least 1 cold drink daily. The study findings also revealed that $26 \%$ children reported their mother or father being overweight, $10 \%$ children had a mother or father with diabetes. $26 \%$ children did not exercise at school, $13 \%$ children do not play outdoors at home and $35 \%$ children spend more time watching TV and playing on computer.

A study was conducted on prevalence of obesity in ambulatory children with intellectual disability revealed that obesity prevalence is unusually high among adults with intellectual disability (ID). A survey was done in nine schools ( $\mathrm{n}=206,150$ boys) for ambulatory children and adolescents with mild-moderate ID in Scotland in 2007. Obesity prevalence observed was compared against Scottish population data on obesity prevalence from the most recent nationally representative survey. Obesity prevalence was $36 \%$, and was significantly higher among those attending secondary schools compared with primary schools. The present study suggests that obesity may be very prevalent among ambulatory children and adolescents with ID, and that increased obesity risk may begin in childhood.

A study was conducted to assess the prevalence of obesity and underweight among school children in the Bright star school. rural and urban areas of Thiruvananthapuram Educational District. A total of 3886 children from 10-15 years of age were screened from rural and urban schools. The results of the study exposed the fact that the percentages of overweight and obese children are growing in both rural and urban areas of Kerala like in other states of India and different of the world. The study also showed that when obesity and overweight were seen more in boys, underweight and severe underweight seemed to be more in girls indicating an increasing trend in the percentage of overweight in boys compared to girls. When the prevalence of overweight and obesity were higher among urban children, the percentage of underweight and severe underweight was higher among rural children.
A cross sectional study was conducted to determine the prevalence of obesity in 3352 school children belonging to affluent society of Mysore city. Prevalence of obesity was calculated in these children. Among children found to be obese, cardio vascular risk factors, life style factors and deitic pattern were evaluated and compared with age and sex matched controls. Cardiovascular risk factors like blood pressure, lipid profile and FBS were evaluated in obese and equal number of age and sex matched controls. Dietic pattern, physical activity, and sedentary activities were recorded by the parents on a pre-tested Performa in cases and controls and the data was further analyzed. The prevalence of childhood obesity is $4.8 \%$ with females $(5.6 \%)$ being slightly more obese than males (4.3\%). Prehypertension (18.9\%) and Hypertension $(24.5 \%)$ were found to be statistically significant in the obese group when compared to the non obese group. Obese children had higher significant risk factors like parental obesity, high birth weight, excess calorie intake and sedentary activities compared to non-obese group.

\section{2) Studies related to effects of dietary patterns on obesity-}

Strong evidence does exist linking children's particular dietary behaviors to the risk of overweight or obesity ${ }^{12}$. These behaviors include, but are not limited to 1) the timing of consumption (e.g., eating breakfast vs. skipping breakfast; number of meals and snacks; eating frequency) breakfast; number, of meals and snacks; eating frequency), 2) the location of consumption (e.g., home vs. away from home), and 3 ) the consumption of beverages. Studies of breakfast and obesity have found varying results across age and gender skipping breakfast may be a risk factor for increased adiposity among older children or adolescents and appears to be more important for girls than for boys.

Longitudinal studies of US adolescents have found that skipping breakfast was associated with increased weight gain from adolescence to adulthood, while eating breakfast was associated with lower BMI.

One cross-sectional study using CSFII 1994-96/98 data found that meal portion sizes, but not snack patterns, were associated with BMI percentile among school-age boys and girls.

One longitudinal study found that meal frequency was inversely related to BMI among girls ages nine to 19years.Black girls that ate three or more meals a day were less likely to be overweight. Snacking frequency does not appear to be related to childhood adiposity, but the evidence is clouded by the lack of consistent definition of snack across research studies. However, beverages consumed by children as snacks Snacking at home has been related to families' fast food purchases and consumption of SSBs (with salty snacks) ,and energy intake and meal patterns appear to be more related to children's BMI than snacking Thus, the frequency of snacking may matter less than what foods and beverages are consumed in these snacks as well as in other meals consumed during the day. Children eat about one-third of their meals away from home, and schools and fast food restaurants are an important source of these meals, together providing more than two thirds meals (and calories) 


\section{International Journal of Science and Research (IJSR) \\ ISSN (Online): 2319-7064}

Index Copernicus Value (2015): 78.96 | Impact Factor (2015): 6.391

consumed away from home. Fried foods consumed away from home are associated with higher energy intakes and body weight and lower consumption of fruits and vegetables among older children and adolescents. Away-from-home foods from fast food and takeout restaurants have increased and are often associated with consumption of energy-dense meals and snacks

\section{3) Studies related to prevention of childhood obesity at school levels-}

A study was conducted to determine a school-based educational program aimed at reducing consumption of carbonated drink can prevent excessive weight gain in children. The study was conducted at six primary schools in southwest England and there was a focus on educational programs on nutrition throughout one school year. The results included a decrease in the consumption of carbonated drinks by 0.6 glasses in the intervention group, but increased by 0.2 glasses in the control group. At 12 months the percentage of overweight and obese children increased in the control group by $7.5 \%$ compared with a decrease in the intervention group by $0.2 \%$. The study concluded that a targeted school-based educational program produced a modest reduction in the number of carbonated drinks consumed, which was associated with a reduction in the number of overweight and obese children.

A study was conducted to evaluate a 12-session home/community- based health promotion/ program (Challenge!) on changes in obese youth. BMI status, body composition, physical activity, and diet. A total of 235 black young children (aged 6-11) years; 38\% overweight/obese) were recruited from low income urban communities. Baseline measures included weight, height, body composition, physical activity(PA), and diet. PA was measured by 7-day play-equivalent physical activity ( $>$ or $=1800$ activity counts per minute). Participants were randomly assigned to health promotion/obesity prevention that is anchored in social cognitive theory and motivational interviewing and was delivered by college-aged black mentors or to control. Post intervention (11 months) and delayed follow-up(24 months) evaluations were conducted. Longitudinal analyses used multilevel models with random intercepts and generalized estimating equations, controlling for baseline age/gender. Stratified analyses examined baseline BMI category. Retention was $76 \%$ over 2 years; overweight/obese status declined 5\% among intervention young children and increased $11 \%$ among control young children. Among overweight/obese youth, the intervention reduced total percentage of body fat and fat mass and increased fat-free mass at delayed follow-up and increased play-equivalent physical activity at post intervention but not at delayed follow-up. Intervention young children declined significantly more in snack/dessert consumption than control adolescents at both follow-up evaluations. At post intervention, there were intervention effects on diet and PA but not BMI category or body composition. At delayed follow-up, dietary changes were sustained and the intervention prevented an increase in BMI category. Body composition was improved for overweight/obese youth. combination with an exercise program and dietary counsellings failed to show a significant reduction in percentage body fat when compared to a control group. This was partly due to the fact that even though the children believed they were eating less their actual calorie consumption did not decrease with the intervention. At the same time observed energy expenditure remained similar between the groups. This occurred even though dietary fat intake decreased from $34 \%$ to $27 \%$.

Another study of 5,106 children showed similar results as above. Even though the children ate an improved diet there was no effect found on BMI. Why these studies did not bring about the desired effect of curbing childhood obesity has been attributed to the interventions not being sufficient enough. Changes were made primarily in the school environment while it is felt that they must occur in the home, the community, and the school simultaneously to have a significant effect.

In a study of 548 children over a 19 month period the likelihood of obesity increased by 1.6 for every additional soft drink consumed per day. Calorie-dense, prepared snacks are available in many locations frequented by children. As childhood obesity has become more prevalent, snack vending machines in school settings have been reduced by law in a small number of localities. Eating at fast food restaurants is very common among young people with $75 \%$ of 4th to 5th grade students consuming fast food in a given week. Some literature has found a relationship between fast food consumption and obesity.

Researchers studied the physical activity of 133 children over a three week period using an accelerator to measure each child's level of physical activity. They discovered the obese children were $35 \%$ less active on school days and $65 \%$ less active on weekends compared to non-obese children . In a fitness survey of 6,000 adults, researchers discovered that $25 \%$ of those who were considered active at ages 7 to 9 were also active adults, compared to $2 \%$ of those who were inactive at ages 7 to 9 , who were now said to be active adults .Staying physically inactive leaves unused energy in the body, most of which is stored as fat. Researchers studied 16 men over a 14 day period and fed them $50 \%$ more of their energy required every day through fats and carbohydrates. They discovered that carbohydrate overfeeding produced $75-85 \%$ excess energy being stored as body fat and fat overfeeding produced $90-95 \%$ storage of excess energy as body fat .Many children fail to exercise because they are spending time doing stationary activities such as computer usage, playing video games or watching television. TV and other technology may be large factors of physically inactive children. Researchers provided a technology questionnaire to 4,561 children, ages 7,8, and 9. They discovered children were $21.5 \%$ more likely to be overweight when watching $4+$ hours of TV per day, $4.5 \%$ more likely to be overweight when using a computer one or more hours per day, and unaffected by potential weight gain from playing video games. ${ }^{14}$ grade children which provided two healthy meals a day in 
Materials and Methods

Sources of Data

School age children in Bright Star matriculate school.

\section{Methodology}

1) Research Approach:

- Quantitative approach.

2) Research Design:

- Descriptive cross section design.

3) Sampling Technique:

- Non - probability convenience sampling technique.

4) Sample And Sample Size :

- Sample size - 30

- Sample-school age children.

\subsection{Setting of the Study}

The will be conducted at Bright star matriculate school. This is CBSE affiliated school. There are 500 school age children studding in the schools. Written permission has been obtained from the Principals to conduct the study.

\subsection{Sampling Criteria}

Inclusion criteria:

Both male female school children with the age group of 15 to 18 years.

\section{Data Collection Tool}

Tool: A structured self administered questionnaire technique will be used to assess the knowledge and attitude of the teachers regarding childhood obesity at selected private primary schools in Bangalore.

Questionnaire will consist of three sections:

Section -1. Proforma for collected demographic data.

\section{Section -2.}

Part 1: Anthropometric Measurment - To measure height and weight to measure body mass index to do classification of body mass index using WHO 2004 criteria $^{42}$.

\section{Part 2:}

Structured self administered questionnaire related to health behavior.

\subsection{Data Analysis Methods}

Data analysis will be done using descriptive and inferential statistics such as Frequency distribution, Percentage, Mean, Standard Deviation, Correlation Coefficient, Chi-Square etc.

Does the Study Require any Investigation or Interventions to be Conducted on Patients or Other Human or Animals?

No. Only self structured questionnaires will be used for data collection. No other invasive or laboratory procedures will be conducted on the samples.

\subsection{Has Ethical Clearance Been Obtained?}

The ethical clearance will be obtained. Confidentiality and anonymity of subjects will be maintained. Consent will be taken from the children before conducting the study.

\subsection{Tools snd Scoring}

1. Means $=$ sum of volume $/$ no of volume

2. Mean deviation $=\mathrm{E}[\mathrm{x}-\mathrm{x}] / \mathrm{n}$

3. $\mathrm{S}$

4. $\mathrm{BMI}=$ weight $(\mathrm{kg}) / \mathrm{height}\left(\mathrm{m}^{2}\right)$

5. $\mathrm{X}^{2}=$

Scoring Schedule
\begin{tabular}{|c|c|}
\hline Adequate knowledge. & Nill \\
\hline Moderate knowledge. & $30 \%$ \\
\hline Inadequate knowledge. & $70 \%$ \\
\hline
\end{tabular}

\section{Pilot Study}

Pilot study was conducted on 11/05/2016 at kuthambakkam area after getting from president of kuthambakkam area. The samples of were selected using convenience sampling techniques .3 samples who met the criteria was selected for the study. The purpose of the study was explained to the sample and their written consent was obtained. Data was collected using structured questionnaire there was no difficult in using the structured questionnaire. Pilot study was found feasible

\section{Main Study}

Main study was conducted on 18.5.2016 to 25.5.2016 at Bright star matriculate school after getting from principal, bright star school. The samples of were selected using convenience sampling techniques .30 samples who met the criteria was selected for the study. The purpose of the study was explained to the sample and their written consent was obtained. Data was collected using structured questionnaire there was no difficult in using the structured questionnaire. Main study was found feasible

\section{Data Analysis and Interpretation}

\section{Analysis and Finding}

The data obtained were mainly classified

Section-I

To determine the distribution of demographic variable

\section{Section - II}

Distribution of level of knowledge among the risk factor.

\section{Section-III}

Association between level knowledge demographic variable. 


\section{International Journal of Science and Research (IJSR) \\ ISSN (Online): 2319-7064 \\ Index Copernicus Value (2015): 78.96 | Impact Factor (2015): 6.391}

Table 1: Frequency and Percentage of Distribution of Demographic Variable among School Age Children

\begin{tabular}{|l|c|c|}
\hline \multicolumn{1}{|c|}{ Demographic Variable } & Frequency & Percentage \\
\hline 1) Age & 3 & \\
a. 15-16 & 3 & 9.99 \\
b. 16-17 & 11 & 9.99 \\
c. 17-18 & 13 & 43.63 \\
d. 18-19 & & \\
\hline 2) Sex & 17 & 56.61 \\
a. Male & 13 & 43.29 \\
b. Female & & \\
\hline 3) Marital Status & 23 & 76.59 \\
a. Unmarried & 7 & 23.31 \\
b. Married & & \\
\hline 4) Family Monthly Income & 2 & 6.66 \\
a. 5000-10000 & 23 & 76.59 \\
b. 10000-20000 & 5 & 16.65 \\
c. 20000-30000 & 0 & 0 \\
d. 30000-40000 & & \\
\hline 5) Residence & 29 & 96.57 \\
a. Rural & 1 & 3.33 \\
b. Urban & & \\
\hline 6) Religion & 28 & 93.24 \\
a. Hindu & 2 & 6.66 \\
b. Muslim & 0 & 0 \\
c. Christian & & \\
\hline 7) No. of children in the family & 5 & 16.65 \\
a. 1 & 21 & 69.93 \\
b. 2 & 0 & 13.32 \\
c. 3 & & 0 \\
d. More than 3 & \\
\hline
\end{tabular}

Table - I

Among 30 children 3(9.99\%) were belongs to the age group of $15-16$ years and $3(9.99 \%)$ were belong to the age of $16-17$ years, and 11(36.63) were belong to the age of 17-18 years and $13(43.29 \%)$ belong to age group above $18-19$ years. Regarding the sex $17(56.61 \%)$ were belong the male and $13(43.29 \%)$ were female. Regarding the marital status belong 23(76.59\%) were unmarried and 7(23.31\%) were belong the married. Regarding the income $2(6.66 \%)$ were $5000-10000$ rupees/month and $23(76.59 \%)$ were the belong $10000-20000$ and 5(16.65\%)belong the 20000 - 30000.regarding the residence $29(96.57 \%$ ) belong the rural and $1(3.33 \%)$ belong the urban. Regarding the religion $28(93.24 \%)$ belong the Hindu and $2(6.66 \%)$ belong the Muslim. Regarding the No. of the children in the family $5(16$. and $65 \%$ ) belong the one child and $21(69.93 \%)$ belong the two child, and $4(13.32 \%)$ children in the family.

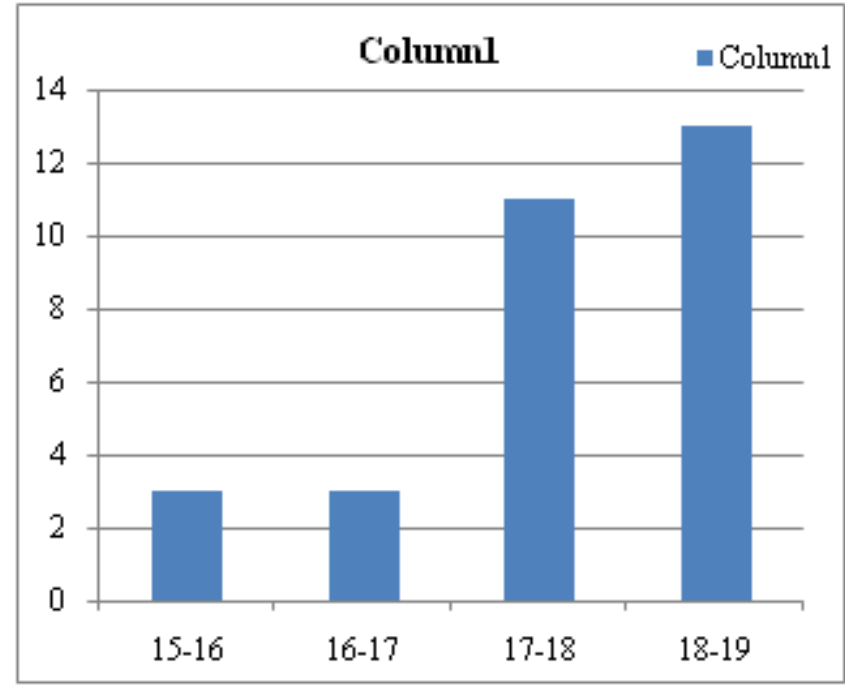

Graphical Representation of Age in Years

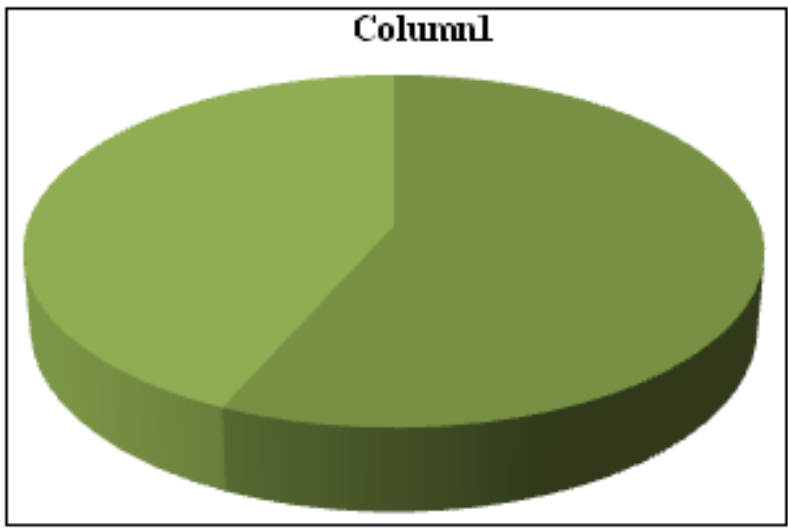

Graphical Representation of Sex

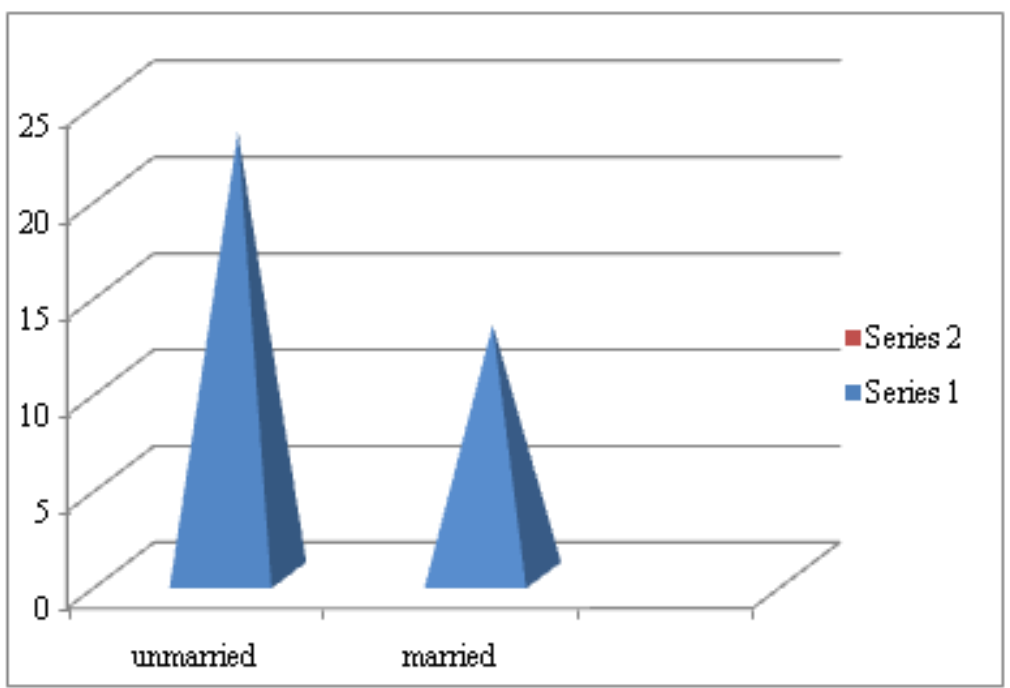

Graphical Representation of Marital Status 
International Journal of Science and Research (IJSR)

ISSN (Online): 2319-7064

Index Copernicus Value (2015): 78.96 | Impact Factor (2015): 6.391

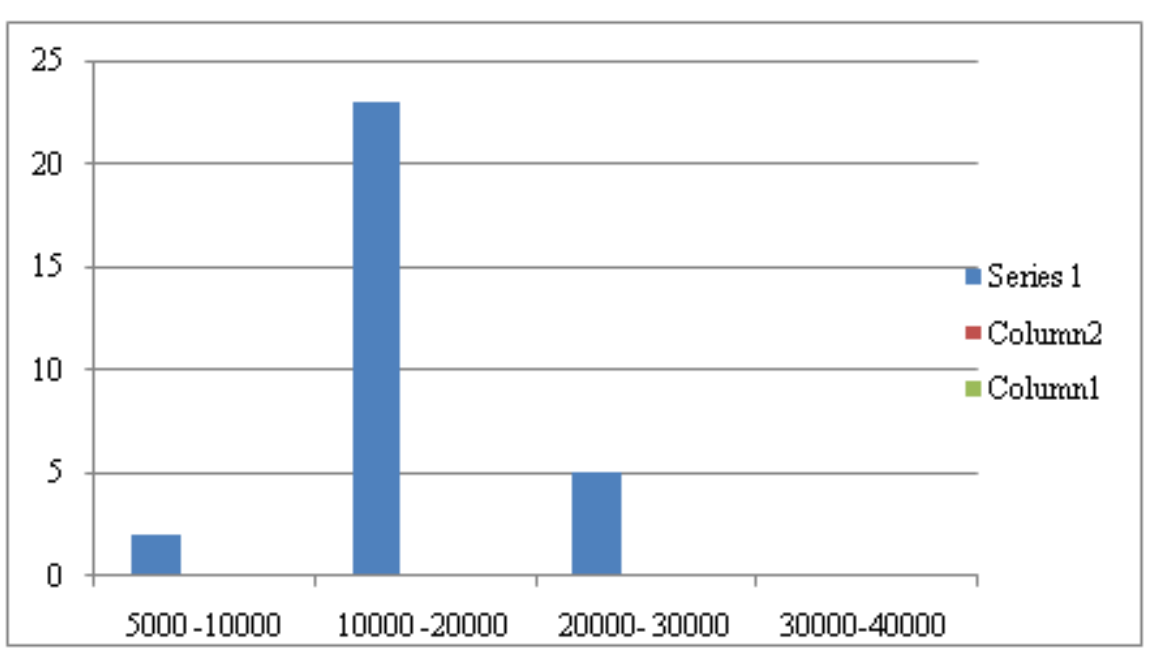

Graphical Representation of Family Income

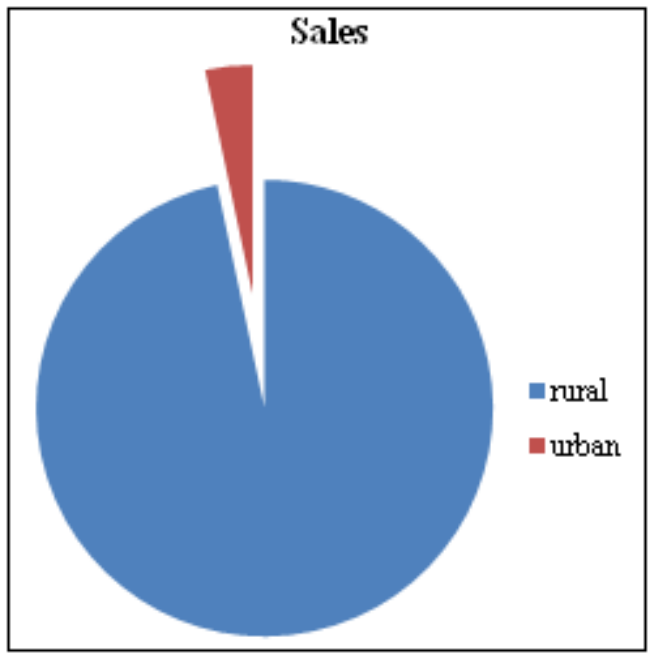

Graphical Representation of Residence

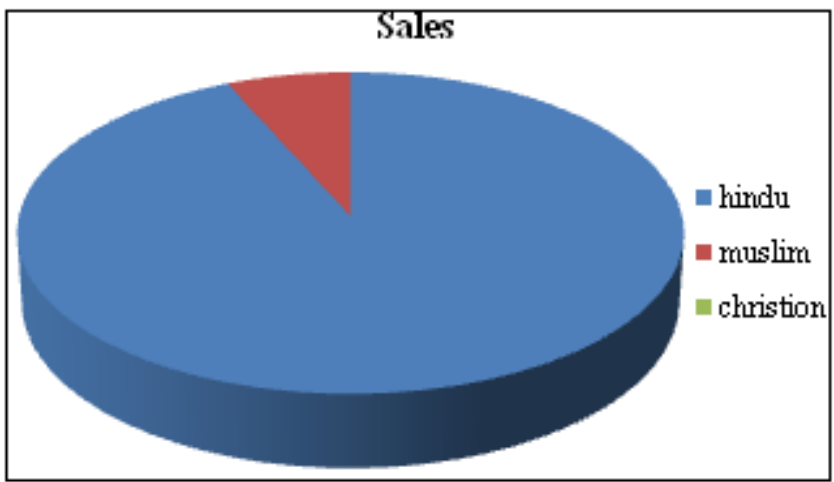

Graphical Representation of Religion

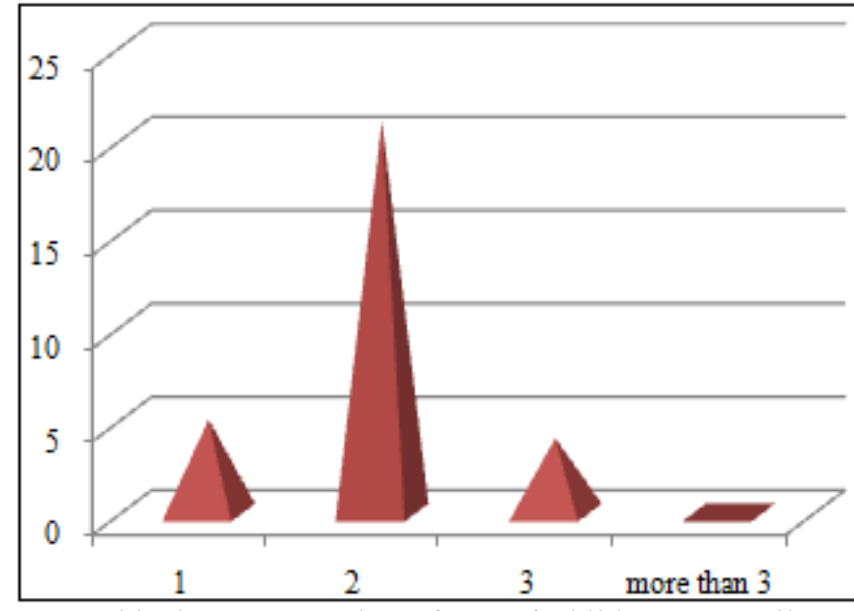

Graphical Representation of No. of Children In Family.

Table II: Frequency and Percentage Distribution among School Age Children.

\begin{tabular}{|c|c|c|c|}
\hline S.No & Level of Knowledge & Frequency & Percentage \\
\hline 1 & Adequate knowledge & 0 & $0 \%$ \\
\hline 2 & Moderately adequate knowledge & 9 & $30 \%$ \\
\hline 3 & Inadequate knowledge & 21 & $70 \%$ \\
\hline
\end{tabular}

Shows among the school age children frequency of adequate knowledge among then is the 0 i.e., about the percentage of $0 \%$. The frequency of moderately adequate knowledge among them are 9 i.e., about percentage of $30 \%$. at last were having inadequate knowledge 21 i.e., about the percentage of $70 \%$. 


\section{International Journal of Science and Research (IJSR) \\ ISSN (Online): 2319-7064}

Index Copernicus Value (2015): 78.96 | Impact Factor (2015): 6.391

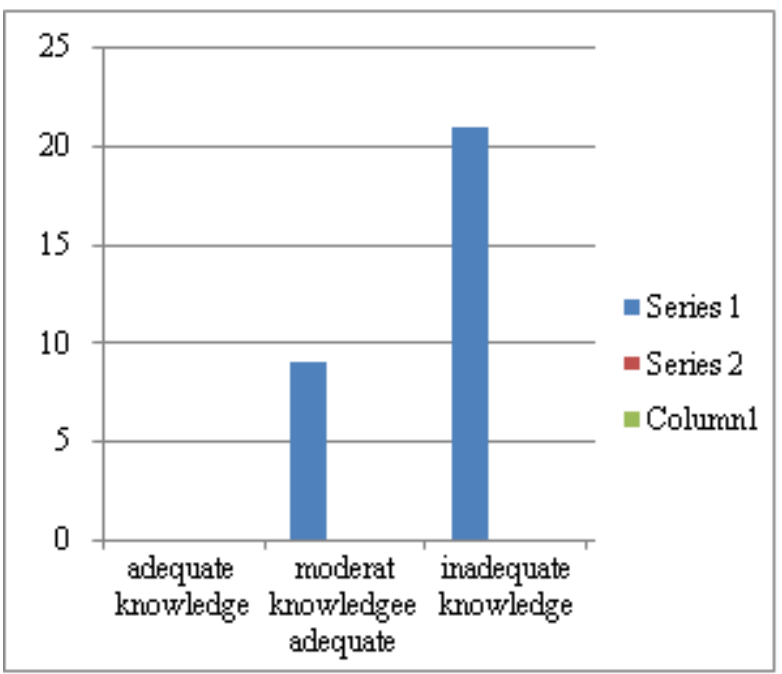

Graphical Representation of Frequency and Percentage Distribution of Knowledge among School Age Children at Bright Star School in Rajasthan

Table 3: Association between Level of Knowledge Among the School Age Children with Selected Demographic Variable

\begin{tabular}{|c|c|c|c|c|c|c|c|c|}
\hline \multirow{2}{*}{$\begin{array}{l}\text { S. } \\
\text { No }\end{array}$} & \multirow{2}{*}{ Demographic Variable } & \multicolumn{2}{|c|}{ Inadequate } & \multicolumn{2}{|c|}{ Moderatly Adequate } & \multicolumn{2}{|c|}{ Adequate } & \multirow{2}{*}{ Chi Square } \\
\hline & & $\mathrm{F}$ & $\%$ & $\mathrm{~F}$ & $\%$ & $\mathrm{~F}$ & $\%$ & \\
\hline \multirow[t]{5}{*}{1} & Age in years & & & & & & & \\
\hline & a. $15-16$ & 2 & $6.66 \%$ & 1 & $3.30 \%$ & 0 & $0 \%$ & \multirow{4}{*}{$\begin{array}{c}X 2=15.30 \\
D f=6 \\
P=12.6\end{array}$} \\
\hline & b. $\quad 16-17$ & 3 & $9.99 \%$ & 0 & $0 \%$ & 0 & $0 \%$ & \\
\hline & c. $17-18$ & 7 & 23.31 & 4 & $13.30 \%$ & 0 & $0 \%$ & \\
\hline & d. $18-19$ & 9 & 29.97 & 4 & $13.30 \%$ & 0 & $0 \%$ & \\
\hline \multirow[t]{3}{*}{2} & SEX & & & & & & & \multirow{3}{*}{$\begin{array}{c}\mathrm{X}^{2}=0.78 \\
\mathrm{DF}=2 \\
\mathrm{P}=5.99\end{array}$} \\
\hline & Male & 13 & 43.27 & 4 & $13.30 \%$ & 0 & $0 \%$ & \\
\hline & b. female & 8 & 26.6 & 5 & $16.60 \%$ & 0 & $0 \%$ & \\
\hline \multirow[t]{4}{*}{3} & Marital status & & & & & & & \\
\hline & a. $\quad$ Married & 4 & $13.30 \%$ & 3 & 9.99 & 0 & $0 \%$ & \multirow{3}{*}{$\begin{array}{c}\mathrm{X} 2=1.18 \\
\mathrm{Df}=4 \\
\mathrm{P}=9.49\end{array}$} \\
\hline & b. unmarried & 17 & 56.57 & 6 & 19.98 & 0 & $0 \%$ & \\
\hline & c. $\quad$ divorce & 0 & 0 & 0 & & 0 & $0 \%$ & \\
\hline \multirow[t]{5}{*}{4} & Monthly income & & & & & & & \\
\hline & $\begin{array}{ll}\text { a. } & 5000-10000\end{array}$ & 1 & $3.33 \%$ & 1 & $3.33 \%$ & 0 & $0 \%$ & \multirow{4}{*}{$\begin{array}{c}\mathrm{X} 2=0.62 \\
\mathrm{Df}=6 \\
\mathrm{P}=12.5\end{array}$} \\
\hline & $10000-20000$ & 16 & $53.20 \%$ & 7 & $23.30 \%$ & 0 & $0 \%$ & \\
\hline & $20000-30000$ & 4 & $13.30 \%$ & 1 & $3.33 \%$ & 0 & $0 \%$ & \\
\hline & $\begin{array}{ll}\text { d. } & 30000-40000\end{array}$ & 0 & $0 \%$ & 0 & $0 \%$ & 0 & $0 \%$ & \\
\hline \multirow[t]{3}{*}{5} & Residence & & & & & & & \multirow{3}{*}{$\begin{array}{c}X^{2}=0.44 \\
D f=2 \\
P=5.93\end{array}$} \\
\hline & a. Rural & 20 & $66.50 \%$ & 9 & 29.97 & 0 & 0 & \\
\hline & b. urban & 1 & $3.33 \%$ & 0 & 0 & 0 & 0 & \\
\hline \multirow[t]{4}{*}{6} & Religion & & & & & & & \\
\hline & a. $\quad H i n d u$ & 19 & 63.17 & 9 & 29.97 & 0 & & \multirow{3}{*}{$\begin{array}{c}X^{2}=0.91 \\
D f=4 \\
P=9.49\end{array}$} \\
\hline & b. $\quad$ Muslim & 2 & 6.66 & 0 & 0 & 0 & & \\
\hline & c. $\quad$ Christian & 0 & 0 & 0 & 0 & 0 & & \\
\hline
\end{tabular}

\section{Table 3}

Shows that was no association between selected demographic variable such as age is the significant. And sex, marital status, income, residence, religion, not significant

\section{Discussion}

Table 1

Among 30 children 3(9.99\%) were belongs to the age group of $15-16$ years and $3(9.99 \%)$ were belong to the age of $16-17$ years, and 11(36.63) were belong to the age of 17-18 years and $13(43.29 \%)$ belong to age group above $18-19$ years.

Regarding the sex $17(56.61 \%)$ were belong the male and $13(43.29 \%)$ were female.
Regarding the marital status belong 23(76.59\%) were unmarried and $7(23.31 \%)$ were belong the married.

Regarding the income $2(6.66 \%)$ were $5000-10000$ rupees/month and $23(76.59 \%)$ were the belong 10000 20000 and 5(16.65\%)belong the $20000-30000$.

Regarding the residence $29(96.57 \%)$ belong the rural and $1(3.33 \%)$ belong the urban.

Regarding the religion 28(93.24\%) belong the Hindu and 2(6.66\%) belong the Muslim. 


\section{International Journal of Science and Research (IJSR) \\ ISSN (Online): 2319-7064 \\ Index Copernicus Value (2015): 78.96 | Impact Factor (2015): 6.391}

Regarding the No. of the children in the family 5(16. and $65 \%$ ) belong the one child and $21(69.93 \%)$ belong the two child, and 4(13.32\%) children in the family.

\section{Table 2}

Shows among the school age children frequency of adequate knowledge among them is the 0 i.e., about the percentage of $0 \%$. The frequency of moderately adequate knowledge among them are 9 i.e., about percentage of $30 \%$. at last were having inadequate knowledge 21 i.e., about the percentage of $70 \%$.

\section{Table 3}

Shows that was no association between selected demographic variable such as age is the significant. And sex, marital status, income, residence, religion, not significant

\section{Summary and Recommendations}

A non experimental research design was undertaken in the study to assess the prevalence and risk factor among the School age children at bright star school in Rajasthan. Samples of 30 school age children were assessed using Nonprobability convenience sampling technique. Structured self administered questionnaire was by the investigator. The data collection from the sample that studying bright star school. The investigator was able to complete the data collection within the stipulated period of 7 days.

\section{Findings Of The Study}

In the study out of 30 children $0(0 \%)$ of them had adequate knowledge, 7(30\%)of them had moderate adequate knowledge and 21(70\%)of them had inadequate knowledge

The overall knowledge mean score on risk factor among the adult were 43 with mean deviation 8 and standard deviation 32.63

There was significant association of age in year. And not significant between the, marital status, monthly income, sex, religion.

\section{Acknowledgement}

The lord has done great things for us, and we are glad. I wish to express our heartfelt gratitude to our LORD ALMIGHTY for the abundant, health, support, encouragement and confidence throughout the dissertation.

I express our sincere and the heart full gratitude to DR. MANGALA GOWRI, R.N.R.M., MSC (N)., PHD. Principal, Saveetha College of nursing, Saveetha University, for her encouragement, valuable suggestion, support and advice given throughout the study.

I wish to express our sincere thank to Mrs. Aruna mam , R.N.R.M., MSC(N) vice principal, college of nursing , saveetha university, Chennai 602105 for her guidance and direction throughout the study
Sincere thank to Mrs. Mary minolin mam B.SC (N)., $\operatorname{MSC}(\mathrm{N})$., Associate professor department of child health nursing , college of nursing ,saveetha university. Chennai 602105 for her guidance, suggestion, and moral support to carry out this project successfully.

I am extremely thankful to all adult people who participate in this study for their full co-operation and interest.

\section{References}

[1] Smeltzer S, Bare B, Hinkle J, Cheever K. Brunner \& Suddarth's Text book of Medical Surgical Nursing. $11^{\text {th }}$ Edition .New Delhi :Lippincott Williams \& Wilkins;2009 p. 855

[2] K PARK - "Text Book of Preventive and Social Medicine", $20^{\text {th }}$ edition, 2009. page no.345

[3] Bharati DR, Deshmukh PR, Garg BS.A Study done on Correlates of Overweight And Obesity among the school going children of Wardha City, Central India. Indian Journal of Medical Research. 2008 Jun; 127(6); 514-5.

[4] Maryam Amini, Nasrin Omidvar, Masood Kimiagar. A Study on prevalence of Overweight and Obesity among junior high school children in a district of Tehran. Journal_of_research_in_Medical_Sciences November and December 2007; Vol 12, No 6: 315-319.

[5] S Kumar, DK Mahabalaraju, MS Anuroopa. A study done on the prevalence of Obesity and Its Influencing factors among Affluent school children of Davangere city in India. Indian Journal of Community Medicine Vol. 32, No. 1(2007-01 -2007-03).

[6] Sidhu Sharda, Marwa Gauri.A study Done on the Prevalence of Overweight and Obesity among affluent adolescent school children of Amritsar, Punjab. Collegium Antropologicum ISSN 0350-6134 2005, vol.29, n 1, pp. 53-55.

[7] Chhatwal J, Verma M, Riar SK.A Study on Obesity among pre-adolescent and Adolescent children in Ludhiana, Punjab. Asia Pac Journal of Clinical Nutrition.2004; 13(3):231-5.

[8] Vedavati Subramanian, Jayashree R, Mohammad Rafi.A study of Overweight And Obesity in Affluent Adolescent Girls in Chennai. Indian Journal of Pediatrics 2003, 40: 332-336.

[9] D'Argenio P and Citarella A. A Study on Obesity and Overweight in Pre- adolescents children in Province of Benevento.BEN-Notiziario ISS 2001 Jan Vol.14-n.1.

\section{Appendices}

\section{साधन[tool] \\ I. जनसांख्यिकीय संबंधी \\ 1. आयु \\ a. $16-15$ \\ b. $17-16$ \\ c. $18-17$ \\ d. $19-18$ \\ 2. लिंग \\ a. पुलिंग \\ b. स्त्रीलिंग \\ 3. विबाहित स्थिति}


a. शादीशुदा

b. कुवारा

4. मासिक आय
a. 10000-5000
b. $20000-10000$
c. $30000-20000$
d. $40000-30000$

5. निवाश स्थान
a. ग्रामीण

b. शहरीय

6. धर्म
a. हिंदु
b. मुस्लिम
c. क्रिश्चियन

7. परिवार मे बच्चे
a. एक
b. दो
c. तीन
d. तीन से ज्यादा

1. मोटापे का मतलव

मोटापे से सम्वदित प्रश्न

$$
\text { C. } \mathrm{a} \text { और } \mathrm{b}
$$

9. आहार

$$
\text { a. शाकाहारी }
$$

10. मोटापे के परिणाम हे
a. उच्च रक्तचाप
b. किडनी की वीमारी
c. सुगर

a. कोसिकाओ मे वसा का वढ्ना

b. कोसिकाओ मे खून का वढ्ना

c. शरीर मे पानी का वढ़ना

2. $\mathrm{BMI}$ की सामान्य मान्यता
a. 24.9- 18.5
b. 40 से ज़्यादा
c. $39.9-30$
d. $29.9-25$

3. खाने मे पसन्द
a. चाट चीज
b. घर पर बनाई
c. नमकीनी चीज

4. तुम्हारी पसन्द की शारीरिक गतिविधी
a. घर के वाहर के खेल
b. घर के अन्दर के खेल
c. विडियो खेल
d. इंटरनेट चेटटिंग

5. तुम्हारी शौक
a. रस्सी से कूदना
b. टीवी देखना
c. किताव पड़ना

6. शारीरिक गतिविधी की अवधि
a. 10 मिनट
b. 20 मिनट
c. 30 मिनट
d. 35 मिनट

7. मोटापे को केसे कम कर सकते हे

a. शारीरिक गतिविधी से

b. डीटिंग

c. उपहास

d. शारीरिक गतिविधी के साथ डीटिंग

8. मोटापे के जोखिम कारक

a. अस्वास्थकर खाध

b. वशानुगत 